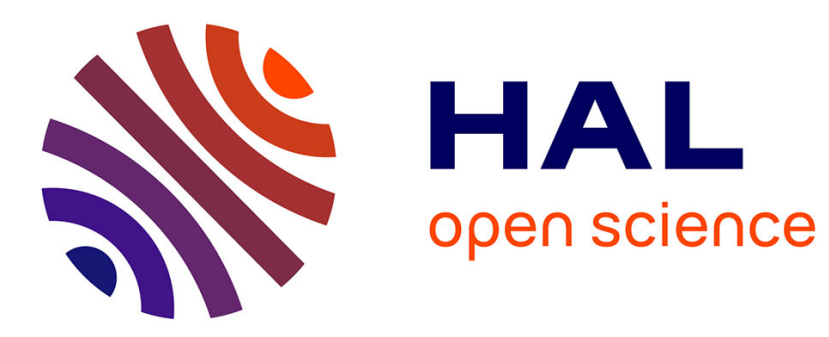

\title{
Individual sensitivity to framing effects
}

Emmanuel Flachaire, Guillaume Hollard

\section{To cite this version:}

Emmanuel Flachaire, Guillaume Hollard. Individual sensitivity to framing effects. Journal of Economic Behavior and Organization, 2008, 67 (1), pp.296. 10.1016/j.jebo.2006.10.006 . hal-00598266

\section{HAL Id: hal-00598266 https://hal.science/hal-00598266}

Submitted on 6 Jun 2011

HAL is a multi-disciplinary open access archive for the deposit and dissemination of scientific research documents, whether they are published or not. The documents may come from teaching and research institutions in France or abroad, or from public or private research centers.
L'archive ouverte pluridisciplinaire HAL, est destinée au dépôt et à la diffusion de documents scientifiques de niveau recherche, publiés ou non, émanant des établissements d'enseignement et de recherche français ou étrangers, des laboratoires publics ou privés. 


\section{Accepted Manuscript}

Title: Individual sensitivity to framing effects

Authors: Emmanuel Flachaire, Guillaume Hollard

PII: $\quad$ S0167-2681(07)00153-9

DOI: $\quad$ doi:10.1016/j.jebo.2006.10.006

Reference: $\quad$ JEBO 2126

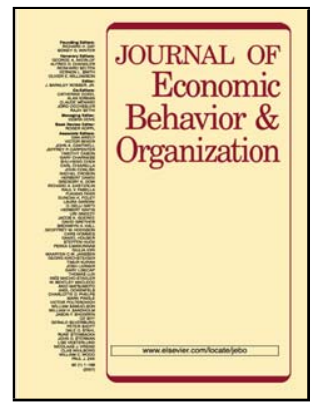

To appear in: Journal of Economic Behavior \& Organization

Received date: $\quad 14-9-2004$

Accepted date: $\quad 3-10-2006$

Please cite this article as: Flachaire, E., Hollard, G., Individual sensitivity to framing effects, Journal of Economic Behavior and Organization (2007), doi:10.1016/j.jebo.2006.10.006

This is a PDF file of an unedited manuscript that has been accepted for publication. As a service to our customers we are providing this early version of the manuscript. The manuscript will undergo copyediting, typesetting, and review of the resulting proof before it is published in its final form. Please note that during the production process errors may be discovered which could affect the content, and all legal disclaimers that apply to the journal pertain. 


\title{
Individual sensitivity to framing effects
}

\author{
by \\ Emmanuel Flachaire \\ Université Paris 1 Panthéon-Sorbonne \\ Maison des Sciences Économiques, \\ 106-112 bd de l' Hopital, \\ 75647 Paris Cedex 13, France \\ emmanuel.flachaire@univ-paris1.fr \\ tel:+33(0)144078214, fax:+33(0)144078231 \\ and

\section{Guillaume Hollard} \\ OEP, Université de Marne la Vallée \\ Pôle du Bois de l'Etang-Cité Descartes \\ 5 bd Descartes, Champs sur Marne \\ 77454 Marne-la-vallée Cedex 2, France \\ hollard@univ-mlv.fr \\ tel:+33(0)144078120, fax:+33(0)144078231
}

May 2007 


\begin{abstract}
Surveys are sometimes viewed with suspicion when used to provide economic values, since they are sensitive to framing effects. However, the extent to which those effects may vary between individuals has received little attention. Are some individuals less sensitive to framing effects than others? We use the theory of social representation to assign to each individual a new variable to serve as a proxy for the individual's sensitivity to framing effects. This allows to gather new and relevant information to limit the impact of framing effects. We examine two framing effects, starting-point bias and willingness-to-pay and willingness-to-accept divergence.
\end{abstract}

Keywords: starting-point bias, wta-wtp divergence, social representation JEL Classification: C81, C90, H43, Q51 


\section{Introduction}

It has long been recognized that the design of a survey may influence respondents' answers. In the particular case in which respondents have to estimate numerical values, this implies that two different surveys may lead to two different valuations of the same object. Such a variation of answers, induced by non-significant change in the survey design, is called a framing effect. Consequently, surveys are sometimes viewed with suspicion when used to provide economic values, since framing effects may alter the quality of survey-based valuation. The existence of these effects is well-documented (Levin et al. 1998). However, the extent to which they may vary between individuals has received little attention. Are some individuals less sensitive to framing effects than others? How to detect them? These are the questions addressed in this paper.

Our basic idea is to use the theory of social representation to assign to each individual a new variable. This variable represents a proxy for the individual's sensitivity to framing effects. According to this representation variable, we isolate two types of individuals. The first type is proved to be less sensitive to framing effects than the other. We examine two framing effects that are known to have a dramatic effect on valuation, namely, starting-point bias and willingness-to-pay (WTP) and willingness-toaccept (WTA) divergence. The results suggest that taking into account heterogenous sensitivity to framing effects is successful in limiting the impact of biases. Furthermore, they prove that the constructed representation variable is not correlated to any of the usual variables. Thus, using the representation variable allows researchers to gather relevant new information.

The paper is organized as follows. Section 2 details how social representation can be used to design a new individual variable. Section 3 presents a study of the problem of starting-point bias in contingent valuation surveys. Section 4 deals with WTA and WTP divergence. Section 5 provides a discussion, and Section 6 concludes.

\section{Representation as a source of heterogeneity}

Representations are defined in a broad sense by social psychologists as a form of knowledge that serves as a basis for perceiving and interpreting reality, as well as for guiding one's behavior. Representation could concern a specific object, or a more general notion of social interest ${ }^{1}$. The founding work (Moscovici 1961) explores the representation of

\footnotetext{
${ }^{1}$ A survey of the theory and methods used to study social representations can be found in Wagner et al. (1999) and Canter and Breakwell (1993)
} 
psychoanalysis. In the following decades, various topics have been investigated: representation of different cities, madness, remarkable places, hunting, AIDS, among others (see the different articles presented in Farr and Moscovici 1984 and Moscovici 1998). The theory of representation has proved useful in the study of economic subjects such as saving and debt (Viaud and Roland-Levy 2000), or the electronic purse (Penz et al. 2004).

The basic structure of a social representation is composed of a central core and of peripheral elements (Abric 1993). The central core contains the most obvious elements commonly associated with the object. They can be viewed as stereotypes or common sense. Those elements are not subject to any dispute, as everyone agrees that they are related to the object described. The core in itself does not contain much information and usually is not a surprise to an observer. The peripheral elements, however, contain fewer consensual elements and are less obvious. They represent potential changes in the social representation and indicate new elements that may in the near future become part of the core. They are, somehow, rivals of the core elements.

There are several ways to explore the composition of social representations of particular subjects (namely, ethnography, interviews, focus-groups, the content analysis of the media, questionnaires and experiments). In what follows, we will focus on a particular technique, which is the statistical analysis of word associations. These word associations are gathered through answers to an open-ended question such as "What are the words that come to mind when thinking of [the object]?" or "What does [the object] evoke to you?". Thus, the purpose of such questions is to investigate the words being spontaneously associated with a given object. The next step is thus to determine the core of the social representation, on the basis of those individual answers. Once the core has been found, we sort individuals according to those who refer to the core of the social representation and those who don't. This "aller-retour" between social and individual representations can be compared to an election system where individual opinions are aggregated, using majority voting. Once individuals have voted, it is possible to recognize who belongs to the majority and who doesn't. All in all, the task is to transform representations (i.e. lists of words) into a quantitative and individual variable.

The method consists of four steps, each of which is illustrated with an example, namely the Camargue representation ${ }^{2}$. The Camargue is a major wetland in the delta of the Rhône (south of France) covering 75.000 hectares. Of exceptional biological diversity, it hosts many fragile ecosystems and is inhabited by numerous species. The survey was administered to 218 visitors to the Camargue at the end of their visit ${ }^{3}$. Note that the

\footnotetext{
${ }^{2}$ This method was originally developed in Flachaire et al. (2007)

${ }^{3}$ See Claeys-Mekdade et al. (1999) for a complete description of the survey
} 
respondents had therefore spent some time in the Camargue.

\section{Step 1: The data: collecting lists of words}

The usual way to collect information on representation is by open-ended questions. More precisely, we use a question such as: "What does [the object] evoke to you?" or "What are the words that come to mind when thinking of [the object]?". Individuals are expected to provide a list of words or expressions. Thus, the data take the form of ordered lists of words. The set of answers typically displays a large number of different words, as each individual provides different answers. Indeed, a great variety of words can be used to describe a given object (Vergès 1994, Wagner et al. 1999).

Application: In our questionnaire, respondents were asked: "What words come to your mind when you think about the Camargue?" More than 300 different words or expressions were obtained.

\section{Step 2: Classification: choosing a typology for words}

An individual representation is captured through an ordered list of words. The high number of different words (say 100 to 500) imposes a categorization (i.e. clustering words that are "close" enough). Choosing a particular categorization thus consists in defining a particular typology for the set of words. Empirical applications typically use six to ten categories that are chosen to form homogeneous categories. This step is the only one that leaves the researcher with some degree of freedom since the notion of proximity is not straightforward.

After categorization, each individual's answer is transformed into an ordered list of categories (rather than a list of words). At the end of this categorization, we are left with individual representations containing doubles, that is, with several attributes belonging to the same category. To obtain transitive individual representations, we suppress the lower-ranking citations belonging to the same category. Such treatment eliminates some information. In our case, the length of individual answers decreased by $20 \%$.

After treatment (i.e. categorization + suppression of doubles), individual representations boil down to an individual ranking of the set of categories.

Application: A basic categorization by frame of reference leads to eight different categories. For instance, the first category is called Fauna and Flora. It contains all the attributes that refer to the animals and local vegetation of the Camargue (fauna, 62 
citations, birds, 44, flora, 44, bulls, 37, horses, 53, flamingos, 36, ...). The other categories are Landscape, Disorientation, Isolation, Preservation, Human presence and Coast. A particular case is the category Nature, which contains only the word nature which can hardly fall into any of the previous categories. There is a ninth category that clusters all attributes that do not refer to any of the categories mentioned above ${ }^{4}$.

\section{Step 3: Finding the core}

The simplest way of determining the core element is to classify the different categories according to their citation rate. The core is thus composed of the category that is most widely used by individuals. This is in accordance with the definition of the core as the most consensual and widely accepted elements associated with a given object.

Application: After consolidating the data in step 2, we were left with 218 ordered lists of categories. We computed the number of appearances for each category. The results are presented in Table 1. The top element, Fauna-Flora, is used by a large number of

\begin{tabular}{ccc}
\hline Category & Citation Rate & Rank \\
\hline \hline Fauna-Flora & $82 \%$ & 1 \\
\hline Landscape & $74 \%$ & 2 \\
Isolation & $58 \%$ & 3 \\
Preservation & $51 \%$ & 4 \\
Human presence & $34 \%$ & 5 \\
Nature & $33 \%$ & 6 \\
Disorientation & $32 \%$ & 7 \\
Coast & $26 \%$ & 8 \\
\hline
\end{tabular}

Table 1: Citation Rank

respondents, $82 \%$. Only a minority do not use any element of this category. This is not a big surprise since the main interest of the Camargue (as presented in all related commercial publications or represented on postcards) is the Fauna and Flora category ${ }^{5}$.

\footnotetext{
${ }^{4}$ After categorization and deletion of doubles, the average number of attributes evoked by the respondents falls from 5.5 to 4.0 .

${ }^{5} \mathrm{~A}$ quick look at any website about the Camargue is also a way of confirming Fauna-Flora as the obvious aspect of the Camargue. Among others, see www.parc-camargue.fr or www.camargue.com.
} 


\section{Step 4: Sorting individuals}

We choose to isolate individuals who do not mention the top element of the social representation (i.e. the core of the social representation). This leads to a breakdown of individuals into two sub-samples: one that contains the individuals who used the core element in their representation and one that contains the individuals who did not.

The main reason for this is that it is remarkable not to mention any of the core elements. It is thus assumed that not mentioning the core is indeed significant. Since it does not conform to most common practice, this group is often referred to as "minority". The other group, which mentions the core element, is referred to as "mainstream".

Application: In the case of the Camargue, the subjects were interviewed at the end of their visit and had seen a lot of animals and plants (they could even see some of them while being interviewed). A small minority of individuals did not refer to Fauna and Flora (18\% of the total population, see Table 1$)$.

Given these four steps, we are left with two categories of individuals. This leads to a breakdown of individuals into two sub-samples: those who refer to the core of the social representation (mainstream) and the others (minority). We can define a mainstream dummy variable, which can be used to control the sensitivity to framing effects. To do so, existing models have to be adapted. In the following, we use this new variable with empirical data, considering two standard framing effects, starting point bias and WTA-WTP divergence.

\section{Starting-point bias}

In contingent valuation, respondents are asked whether they are willing to pay a fixed sum of money for a given policy to be implemented. This discrete choice format is recommended by the NOAA panel over other methods (a panel of experts that sets guidelines to run evaluation surveys; see Arrow et al. 1993). This "take it or leave it" format mimics a market situation that individuals face in everyday market transactions, and it is incentive-compatible. However, a major drawback is that it leads to a qualitative dependent variable (the respondent answers yes or no), which reveals little about the individual's willingness-to-pay (WTP). To gather more information on respondents' WTP, Hanemann (1985) and Carson (1985) proposed adding a follow-up discrete choice question to improve the efficiency of discrete choice questionnaires. This mechanism is known as the double bounded model. It basically consists of proposing a second bid to the respondent, greater than the first bid, if the respondent's first answer is yes, and 
lower otherwise.

Several studies have found that estimates of the mean of willingness-to-pay are substantially different from estimates based on the first question alone. This is the so-called starting-point bias (Herriges and Shogren 1996), which can be seen as a particular case of the anchoring bias put forward by Tversky and Kahneman $(1974)^{6}$. Different models have been proposed in the literature to control for such undesirable effects. However, empirical results suggest that efficiency gains obtained with follow-up questions are lost relative to models using first questions only. All these models assume that all individuals are equally sensitive to starting-point bias. In this section, we consider that some individuals may be more sensitive than others to starting-point bias. We develop a model to handle starting-point bias with heterogeneity in two groups. An application shows that, with individual sensitivity to starting-point bias, we can control for starting-point bias with efficiency gains.

\subsection{Model}

Different models are proposed in the literature to control for starting-point bias in double-bounded models. All of these models assume that the second answer is sensitive to the first bid offer, in the sense that a prior willingness-to-pay $W_{i}$ is used by the respondent $i$ to respond to the first bid offer, $b_{1 i}$, and an updated willingness-to-pay $W_{i}^{\prime}$ is used to respond to the second bid, $b_{2 i}$. Each model leads to a specific definition of $W_{i}^{\prime}$. Whitehead (2002) proposes a general model, combining several effects, as follows:

$$
W_{i}^{\prime}=W_{i}+\gamma\left(b_{1 i}-W_{i}\right)+\delta,
$$

where $\gamma$ and $\delta$ are two parameters. If $\delta=0$ this model corresponds to the Anchoring model proposed by Herriges and Shogren (1996), where the respondents combine their prior WTP with the value provided by the first bid, such that the first bid offer plays the role of an anchor. The parameter $\gamma$ measures the strength of the anchoring effect $(0 \leq \gamma \leq 1)$. If $\gamma=0$ this model corresponds to the Shift model proposed by Alberini et al. (1997), where the WTP systematically shifts between the two answers. The first bid offer is thus interpreted as providing information about the cost or the quality of the object: a respondent can interpret a higher bid offer as paying more for the same object

\footnotetext{
${ }^{6}$ The anchoring bias appears in experimental settings in which subjects are asked to provide numerical estimations (e.g. the height of Mount Everest). Prior to the estimation stage, they are asked to compare their value to an externally provided value (e.g. 20.000 feet). This last value received the name of anchor as it was proved to have a great influence on subjects' valuations (i.e. a different anchor, or starting point, leads to a different valuation)
} 
and a lower bid offer as paying less for a lower quality object. The model (1) combines both Anchoring and Shift effects.

In model (1), all individuals are supposed to be sensitive to the first bid offer in the same manner: the two parameters $\gamma$ and $\delta$ are constant across individuals. If only some respondents are influenced by the first bid (i.e. they combine their prior WTP with the first bid), while the others do not, individual heterogeneity is present. It is well known that econometric estimation of regression models can be seriously misleading if such heterogeneity is not taken into account. Let us assume that we can divide respondents into two distinct groups: one group subject to starting-point bias and another insensitive. We define a Heterogenous model as

$$
W_{i}^{\prime}=\left\{\begin{array}{lll}
W_{i} & \text { if } & I_{i}=0 \\
W_{i}+\gamma\left(b_{1 i}-W_{i}\right)+\delta & \text { if } & I_{i}=1
\end{array}\right.
$$

where $I_{i}$ is a dummy variable that is equal to 1 when individual $i$ belongs to one group and 0 if he belongs to the other group. Note that, if $I_{i}=1$ for all respondents, this model reduces to the Anchoring $\&$ Shift model ; if $I_{i}=0$ for all respondents, it reduces to the standard Double-bounded model.

These models can be estimated with random effect probit models, taking into account the dynamic aspect of follow-up questions (Cameron and Quiggin 1994, Alberini et al. 1997, Whitehead 2004). Estimation requires simulated methods and a formal definition of the probability that the individual $i$ answers yes to the $j^{\text {th }}$ question, $j=1,2$. For the heterogenous model (2), we calculate this probability, which is equal to

$$
P\left(W_{j i}>b_{j i}\right)=\Phi\left[X_{i} \alpha-\frac{1}{\sigma} b_{j i}+\theta\left(b_{1 i}-b_{j i}\right) I_{i} D_{j}+\lambda I_{i} D_{j}\right]
$$

where $D_{1}=0$ and $D_{2}=1, \alpha=\beta / \sigma, \theta=\gamma /(\sigma-\gamma \sigma)$ and $\lambda=\delta /(\sigma-\gamma \sigma)$. Based on this equation, the parameters are interrelated according to

$$
\beta=\alpha \sigma, \quad \gamma=\theta \sigma /(1+\theta \sigma) \quad \text { and } \quad \delta=\lambda \sigma(1-\gamma) .
$$

Implementation of the Double-bounded model is obtained with $\delta=\gamma=0$, which corresponds to $\theta=\lambda=0$ in (3). Implementation of the Anchoring $\&$ Shift model is obtained with $I_{i}=1$ for $i=1, \ldots, n$. For a more detailed discussion on the estimation of a random effect probit model, see Alberini et al. (1997) and Whitehead (2004).

\subsection{Results}

We use the dummy variable mainstream, defined in the previous section, and the Camargue survey to conduct an application. In practice, a value of particular interest is 
the estimate of the WTP mean. Once a model has been estimated, we can obtain fitted values $\hat{W}_{i}$, for $i=1, \ldots, n$, from which we can calculate the estimate of the mean of WTP: $\hat{\mu}=n^{-1} \sum_{i=1}^{n} \hat{W}_{i}$. We estimate the mean values of WTP from a linear model (MacFadden and Leonard 1993) and compute the confidence intervals by simulation with the Krinsky and Robb procedure (see Haab and McConnell 2003, ch.4). Table 2 presents estimates of the WTP mean, obtained from the Double-bounded, Anchoring \& Shift and Heterogeneous models. We include estimates obtained from the Single-bounded, taking into account the first answers only. The analysis is based on two criteria: whether the mean of WTP is consistent (consistency) and whether the standard errors are more precise (efficiency) with those obtained from the Single-bounded model.

\begin{tabular}{ccccc}
\hline Model & WTP mean & conf. interval & consistency & efficiency \\
\hline \hline Single-bounded & 113.5 & {$[98.1 ; 138.2]$} & & \\
\hline Double-bounded & 89.8 & {$[84.4 ; 96.5]$} & no & yes \\
Anchoring 6 Shift & 158.5 & {$[122.6 ; 210.7]$} & yes & no \\
Heterogeneous & 110.1 & {$[99.0 ; 125.2]$} & yes & yes \\
\hline
\end{tabular}

Table 2: Estimation of the mean of willingness-to-pay

The Single-bounded and Double-bounded models give very different WTP means: 113.5 and 89.8. Their confidence intervals do not overlap. Such inconsistent results suggest that follow-up questions generate starting-point bias in the Double-bounded model.

To control for starting-point bias, we estimate an Anchoring 8 Shift model. The WTP mean is equal to 158.5. It is still very different from the WTP mean obtained from the Single-bounded model (113.5); however, the two confidence intervals overlap slightly. Note that the confidence interval is very wide and the gain in precision obtained by using follow-up questions is lost, a result suggested by Herriges and Shogren.

The Heterogeneous model gives a WTP mean of 110.1. It is very close to the 113.5 obtained from the Single-bounded model. Moreover, the confidence interval obtained from the Heterogeneous model $([99.0 ; 125.2])$ is entirely contained in the confidence interval obtained from the Single-bounded model $([98.1 ; 138.2])$, and thus is narrower. In other words, the Heterogeneous model provides consistent results with the Single-bounded model and is more precise.

Table 3 presents the full econometric results, that is, all the parameter estimates, with the standard errors given in italics. It is clear from this table that using follow-up questions (Double-bounded, Anchoring $\&$ Shift and Heterogenous models) provides significantly reduced standard errors, compared to using first answers only (Single-bounded 


\begin{tabular}{|c|c|c|c|c|c|c|c|c|}
\hline \multirow{2}{*}{$\begin{array}{l}\text { Variables } \\
\alpha_{1}: \text { Constant }\end{array}$} & \multicolumn{2}{|c|}{ Single } & \multicolumn{2}{|c|}{ Double } & \multicolumn{2}{|c|}{ Anch $\& 3$ Shift } & \multicolumn{2}{|c|}{ Heterogeneous } \\
\hline & 0.77 & .993 & 1.11 & .665 & 0.80 & .676 & 1.13 & .677 \\
\hline$\alpha_{2}:$ Distance home-site & 0.20 & .073 & 0.08 & .037 & 0.07 & .038 & 0.07 & .038 \\
\hline$\alpha_{3}$ : Using a car to arrive & -1.35 & .658 & -0.89 & .334 & -0.94 & .335 & -0.96 & .339 \\
\hline$\alpha_{4}:$ Employee & 2.11 & .667 & 1.11 & .382 & 1.02 & .382 & 1.12 & .386 \\
\hline$\alpha_{5}:$ Middle class & 2.42 & .638 & 1.22 & .361 & 1.23 & .363 & 1.28 & .369 \\
\hline$\alpha_{6}:$ Inactive & 1.15 & .667 & 0.83 & .416 & 0.71 & .418 & 0.81 & .419 \\
\hline$\alpha_{7}:$ Working class & 2.14 & .924 & 1.02 & .523 & 1.01 & .528 & 1.09 & .534 \\
\hline$\alpha_{8}:$ White collar & 1.77 & .514 & 0.99 & .318 & 0.97 & .318 & 1.03 & .323 \\
\hline$\alpha_{9}$ : Visiting with family & 0.10 & .501 & 0.18 & .338 & 0.12 & .336 & 0.16 & .341 \\
\hline$\alpha_{10}:$ Visiting alone & 1.34 & 1.01 & 1.41 & .639 & 1.40 & .641 & 1.45 & .652 \\
\hline$\alpha_{11}$ : Visiting with a group & 0.98 & .733 & -0.12 & .422 & 0.04 & .423 & 0.06 & .426 \\
\hline$\alpha_{12}:$ First visit & 1.13 & .458 & 0.18 & .212 & 0.23 & .214 & 0.27 & .219 \\
\hline$\alpha_{13}:$ New facilities proposed & 1.25 & .393 & 0.67 & .201 & 0.66 & .201 & 0.69 & .203 \\
\hline$\alpha_{14}:$ Other financing proposed & -0.70 & .337 & -0.35 & .193 & -0.33 & .194 & -0.34 & .195 \\
\hline$\alpha_{15}:$ South-West & -0.53 & .558 & -0.54 & .387 & -0.51 & .390 & -0.50 & .390 \\
\hline$\alpha_{16}:$ South-East & 0.92 & .721 & 0.62 & .428 & 0.56 & .430 & 0.63 & .431 \\
\hline$\alpha_{17}:$ Questionnaire type & -0.62 & .314 & -0.22 & .184 & -0.20 & .186 & -0.22 & .187 \\
\hline$\alpha_{18}:$ Investigator 1 & 0.51 & .716 & 0.11 & .435 & 0.08 & .439 & 0.14 & .437 \\
\hline$\alpha_{19}:$ Investigator 2 & -0.37 & .769 & -0.45 & .475 & -0.42 & .479 & -0.45 & .478 \\
\hline$\sigma$ & 45.3 & 17.9 & 52.6 & 10.0 & 100.8 & 53.5 & 64.7 & 17.5 \\
\hline$\gamma$ & - & & & & 0.46 & 0.29 & 0.26 & 0.22 \\
\hline$\delta$ & - & & - & & -17.1 & 13.9 & -9.9 & 7.7 \\
\hline$\rho$ & - & & 0.71 & & 0.73 & & 0.77 & \\
\hline
\end{tabular}

Table 3: Random effects probit models (standard errors in italics)

model). Moreover, the precision of the parameter estimates of the regressors is quite similar for the different models using follow-up questions. The anchoring parameter $\gamma$ is statistically significant when we perform a likelihood-ratio (LR) test of the null hypothesis $\gamma=0$, not the shift parameter $\delta$. It suggests that when the minority group is not sensitive to starting-point bias $(\gamma=0$, see equation 2$)$, the mainstream group is significantly subject to such an effect $(\hat{\gamma}=0.26$, with $0 \leq \hat{\gamma} \leq 1)$.

Finally, the Heterogeneous model performs better than the others: it provides consistent results with the Single-bounded model and greatly improves the precision of the estimation. This suggests that taking into acount an individual sensitivity to startingpoint bias does indeed matter. 


\section{WTA and WTP divergence}

Over the past twenty years, a large pattern of empirical evidence has accumulated suggesting a significant divergence between willingness-to-pay (WTP) measures of value, where individuals have to pay for a given object or policy, and willingness-to-accept (WTA) measures of value, where individuals sell the same object or receive money to compensate for the suppression of the same policy (Brookshire and Coursey 1987). Economic theory suggests that, with small income effects, WTP and WTA should be equivalent. Results from a meta-analysis however prove that the divergence, measured by the ratio WTA/WTP, is often high (i.e. the ratio largely exceeds one) (Sayman and Öncüler 2005). Since valuation measures are used for the study of many public-policy questions, these results raise questions about which procedure to use in practice.

The divergence is frequent but can be controlled for. The existence of substitutes has been proved to play an important role (Shogren et al. 1994). In the case of private goods the divergence disappears if subjects are recruited among experienced dealers (List 2003, 2004). This suggests that individuals may learn to avoid the divergence. This intuition is confirmed by the design of an experimental protocol that eliminates the divergence (Plott and Zeiler 2005). The basic ingredients of this protocol are the existence of training rounds and the use of incentive-compatible mechanisms. Taken together, the previous results suggest that subjects may learn to overcome the divergence within a short period of time. These results, however, apply to private goods. If we consider the valuation of some public policy, the time between the survey and the implementation of the policy is too long to implement training rounds. This is the reason why being able to detect subjects who are prone to framing effects is of particular interest for contingent valuations.

\section{$4.1 \quad$ Survey}

To measure the discrepancy between WTA and WTP for public goods, we needed to find a public good that can be sold or withdrawn, or bought or provided. Such public goods are not the most common ones. However, we were lucky enough to be offered a golden opportunity. The University of Marne la Vallée (France) was considering changing its Saturday morning classes policy. The growing number of students led to an increasing number of classes on Saturday morning due to the lack of available classrooms. Students started to protest and asked for a clarification of the policy regarding classes on Saturday morning. Two options were considered. Some students were told they would pay lower fees if they accepted classes scheduled on Saturday, since the university could then rent 
the extra classroom during the week to movie companies to use for filming on location. Other students were offered the option of avoiding Saturday classes by paying higher fees, as the university would have to rent an extra building. Therefore, the trade-off was between paying more to avoid Saturday classes and being paid to attend them. Note that even though the survey concerned students, it was used to take a real decision. Thus, answers to this particular survey had an impact on the respondents' welfare.

We conducted a contingent valuation survey to evaluate both the willingness to pay to avoid classes on Saturday and the willingness to accept classes on Saturday morning. The survey was given to 359 students at the University of Marne La Vallée: 184 individuals were given the WTP version, 175 the WTA one (subjects were randomly assigned to one version).

\section{$4.2 \quad$ Heterogeneity}

Gathering information on social representations using an additional open-ended question leads to our four-step methodology. We propose here to simplify this treatment by running this methodology on a sample of subjects, at a pre-test stage, to identify the items that capture most of the opposition between mainstream and minority. This allows us to detect mainstream and minority using a simple discrete choice question. This greatly simplified the exploitation of the data. While the use of an open-ended question implies a specific treatment (categorization and so on), the use of a simple question does away with the need for any treatment.

Prior to the survey, we elicited the representations "of classes on Saturday morning". Quite surprisingly, the survey revealed two groups that differ more broadly on their vision of university rather than on their vision of Saturday morning (we were expecting more precise reasons, such as the opportunity to have a job on Saturday morning, religious reasons). For the mainstream, the main goal of their studies is to get diplomas, while the minority consider that the most important thing to get from university is skills. Following our method, we then decided to include in the contingent valuation survey an additional question labeled as follows:

In your opinion, the main purpose of your studies is to get:

$$
\text { 1. diplomas } 2 \text { skills }
$$

The two items were presented in a random order. As expected, a large majority, $71 \%$, of the 359 respondents, chose the first option (diplomas), and only a minority chose the second option (skills). We now propose to explore the impact of this distinction on the WTA-WTP divergence. 


\subsection{Results}

Table 4 shows the WTP and WTA means for all the students $(384,175$ for the WTA version and 184 for the WTP version) and for the two sub-groups (those who answer Diplomas and those who answer Skills). The last line presents the WTA/WTP ratio.

\begin{tabular}{cccc}
\hline & All & Diplomas & Skills \\
\hline \hline WTA & 68.7 & 71.9 & 62.5 \\
WTP & 15.3 & 12.5 & 23.3 \\
\hline Ratio & 4.5 & 5.8 & 2.7 \\
\hline
\end{tabular}

Table 4: WTA/WTP divergence

If we neglect the distinction among respondents, the WTA and WTP means are very different, respectively equal to 68.7 and 15.3. The WTA/WTP ratio largely exceeds one and is equal to 4.5. Then, we calculate the WTA and WTP means for individuals who answered the question (diplomas and skills) separately. When we consider the mainstream group (Diplomas), the discrepancy between WTA and WTP is wide and the ratio higher (5.8). However, when we consider the minority group (Skills), the discrepancy and the ratio (2.7) are significantly reduced. Students from the minority group are less sensitive to the WTA and WTP divergence. Even if the discrepancy is not completely removed, the mainstream variable allows us to separate the whole population into two groups that highly differ in their sensibility to framing effects since the ratio falls from 5.8 for the mainstream group to 2.7 for the minority.

\section{$5 \quad$ Further results and discussion}

The previous results show that it is possible to extract information on individual representation for a given object and that it can be successfully used as a good proxy for the individual sensibility to framing effects. Evidence was presented for two distinct sets of data and two different well-known framing effects. Thus far, we have basically found a statistically significant relationship between the mainstream variable and the sensitivity to framing effects. The remaining question is thus why does this occur? The first section proves that the representation variable conveys new information that is not related to other individual characteristics. The second section proposes an interpretation of the link between social representation and framing effects. General considerations on social representation are given in a third section. The last section deals with possible improvements to the proposed approach. 


\subsection{Does representation provide new information?}

Here, we check whether the dummy variable, based on social representation, is correlated with some other individual characteristics.

\begin{tabular}{lc}
\hline Variables & Correlation \\
\hline \hline Distance from home-site & $0.06(0.38)$ \\
Using a car to arrive & $0.09(0.18)$ \\
Employee & $0.01(0.86)$ \\
Middle class & $0.02(0.76)$ \\
Inactive & $0.05(0.42)$ \\
Working class & $0.08(0.22)$ \\
White collar & $0.06(0.35)$ \\
Visiting with family & $0.07(0.27)$ \\
Visiting alone & $0.06(0.36)$ \\
Visiting with a group & $0.01(0.84)$ \\
Visiting the site for the first time & $0.12(0.08)$ \\
New facilities proposed & $0.01(0.82)$ \\
Other financing proposed & $0.05(0.42)$ \\
South-West & $0.08(0.24)$ \\
South-East & $0.02(0.77)$ \\
Questionnaire type & $0.07(0.32)$ \\
Investigator 1 & $0.00(0.93)$ \\
Investigator 2 & $0.01(0.85)$ \\
\hline
\end{tabular}

Table 5: The Camargue survey: correlation coefficient.

First consider the Camargue survey. Table 5 shows the Pearson correlation coefficient $\rho$ between the mainstream dummy variable and the regressors included in the regression model. A $P$-value is given in parenthesis for the null hypothesis $\rho=0$. We can see that in all cases, the null is rejected (all the P-values are greater than 0.05). It suggests that the dummy variable is not correlated to the regressors.

Second, consider the Saturday classes survey. Table 6 shows the Pearson correlation coefficient $\rho$ between the Diplomas/Skills dummy variable and other questions from the questionnaire. A $P$-value is given in parenthesis for the null hypothesis $\rho=0$. We can see that in all cases, the null is rejected (all the P-values are greater than 0.05). Again, it suggests that the dummy variable is not correlated to the regressors.

These results suggest that the information obtained from individual representation cannot be captured by the use of standard individual characteristics. In this sense, it is new information, not related to standard questions in surveys. 


\begin{tabular}{lc}
\hline Variables & Correlation \\
\hline \hline grant holder & $0.01(0.93)$ \\
Saturday job & $-0.05(0.29)$ \\
Birth year & $0.08(0.14)$ \\
Sex & $0.05(0.31)$ \\
Feeling of achievement & $-0.03(0.56)$ \\
Education (mother) & $-0.02(0.77)$ \\
Education (father) & $-0.11(0.08)$ \\
Education (self) & $-0.10(0.05)$ \\
Opinion on the decision process & $0.00(0.99)$ \\
\hline
\end{tabular}

Table 6: Saturday classes survey: correlation coefficient.

\subsection{From representation to framing effects}

Thus far, we have concentrated on the most technical aspects, based on statistical evidence. Here, we propose an interpretation about why representations can be linked to framing effects. This interpretation relies on three distinct arguments. The first two are nothing more than an application of general ideas developed in psychology and sociology. The key argument is thus the third one.

1. Our use of social representation is very classical on some points and more original on others. Identifying the core and peripheral elements of a social representation on the basis of a statistical analysis of word associations is a classic in social psychology. It is also admitted that peripheral elements are identified by a minority. Our approach thus consists in pooling all minorities in one group.

2. The next step of our reasoning is to assume that these individuals are conscious of not being members of the mainstream, while others may just follow the crowd with no clear consciousness of doing so. The idea that members of the minority have a more accurate perception of their identity is generally accepted in sociology. Thus, we associate a classical sociological argument with a more psychological one.

3. The core idea of our work is that the minority group on a particular subject has a stronger opinion (i.e. a more personal or elaborate point of view) ${ }^{7}$. Thus, the minority is more likely to resist outside influences and is therefore less sensitive to framing effects.

\footnotetext{
${ }^{7}$ Note that we do not exclude that some individuals may have a strong point of view that is in accordance with that of the mainstream. We only suggest that we can isolate some individuals holding a strong point of view.
} 


\subsection{Representation as a marker of past experience}

If you have never coped with an object or a situation in the past in the past, you are very likely to handle it at first glance in a very predictable way, using common sense or stereotypes (this is what the core represents) but if for any reason, you have been confronted with this problem in the past, it is very likely that you start recomposing your representation of this object or situation (you don't have the same representation of Paris once you've been there). According to that view, non-mainstream representations are then a consequence of past experiences. Representations can thus be thought of as a fast and frugal way to capture information about past experiences.

If we now concentrate on the problem of eliciting preferences (say for public decision making), representations allow us to isolate individuals that have somehow "invested" in their own preference. We expect them to hold a stronger opinion and have more stable preferences, thus being less sensitive to framing effects.

Such a distinction is similar to the debate on the origin of individual preferences (Slovic 1991). Members of the minority are assumed to be individuals who have set their preferences, while some members of the mainstream population are assumed to construct their preferences through the elicitation process. Our results suggest how to identify individuals who have set their preferences before the elicitation process begins. The existence of such a population is not a surprise since in any experiments that intend to detect biases, a small, but significant part of the subjects do not exhibit pathological preferences (among many references, see the experiments in Kahneman and Tversky 2000). This paper is a first step towards detecting such individuals.

\subsection{Criticism, improvements and further research}

The proposed method has reached the goal of proving that a substantial heterogeneity relative to the sensitivity to framing effects exists, even in socially very homogenous populations such as students. The agenda for further research includes the design of more subtle tools to classify individuals. Here, we are able to isolate a population that proves to be much less sensitive to framing effects than the residual population. One can think of a more continuous variable that measures the sensitivity to framing effects.

The proposed methodology is open to criticism at two distinct levels. As we are exploiting an open-ended question, a choice has to be made on how to categorize the answers. A good classification requires the creation of homogeneous categories. Even 
though our classification ${ }^{8}$ tends to demonstrate the presence of individual sensitivity to framing effects, another choice could be considered. A second criticism may concern the way we construct the two subpopulations on the basis of the social representation. Our choice is to put respondents who cite the most cited category in a mainstream group, and the others in the minority group. Other choices and alternatives splits (with more than two groups) could be used. Finally, our dichotomous split has done a good job as a first step, but further research may help us to understand better the determinants of individual sensitivity to framing effects.

\section{Conclusion}

This paper is a first step towards approaching heterogeneity relative to the sensitivity to framing effects. A simple tool is designed to detect a group of individuals who is proved to be far less sensitive to framing effects than the reference population. This approach is effective on two distinct sets of data concerning different framing effects. This raises important questions at the normative level. How should values be set within heterogeneous groups? Should the values be computed using only the values of those detected as not sensitive to framing effects?

\section{Acknowledgements}

The authors thank Jason Shogren and two anonymous referees for useful comments.

\section{References}

Abric, J., 1993. Central system, peripheral system: their functions and roles in the dynamics of social representation. Papers on social representation $2 / 2,77-80$.

Alberini, A., Kanninen, B., Carson, R., 1997. Modeling response incentive effects in dichotomous choice valuation data. Land Economics 73, 309-324.

Arrow, K., Solow, R., Portney, P.R., Leamer, E.E., Radner, R., Schuman, H., 1993. Report of the NOAA panel on contingent valuation. Technical Report 58, 16011614.

Brookshire, D., Coursey, D., 1987. Measuring the value of a public good: an empirical comparison of elicitation procedures. American Economic Review 77, 554-556.

\footnotetext{
${ }^{8} \mathrm{~A}$ full description of the one we used is available in Hollard and Luchini (1999)
} 
Cameron, T., Quiggin, J., 1994. Estimation using contingent valuation data from a dichotomous choice with follow-up questionnaire. Journal of Environmental Economics and Management 27, 218-234.

Canter, D., Breakwell, G., 1993. Empirical approaches to social representation. Oxford: Clarendon Press.

Carson, R., 1985. Three essays on contingent valuation (welfare economics, non-market goods, water quality. Ph.D dissertation, Department of agricultural economics and resource economics, University of California, Berkeley.

Claeys-Mekdade, C., Geniaux, G., Luchini, S., 1999. Quelle valeur attribuer à la Camargue? une perspective interdisciplinaire économie et sociologie. In: Point, P.M. (Ed.), La valeur économique des hydrosystèmes. Méthodes et modèles d'évaluation des services délivrés. Economica, Paris, pp. 137-168.

Farr, R., Moscovici, S., 1984. Social representations. Cambridge: Cambridge University Press.

Flachaire, E., Hollard, G., Luchini, S., 2007. Heterogeneous anchoring in dichotomous choice valuation frameweork. Louvain Economic Review, forthcoming.

Haab, T.C., McConnell, K.E. 2003. Valuing Environmental and Natural Resources. Northampton: Edwar Elgar.

Hanemann, W.M., 1985. Some issues in continuous and discrete response contingent valuation studies. Northeastern Journal of Agricultural Economics 14, 5-13.

Herriges, J., Shogren, J., 1996. Starting point bias in dichotomous choice valuation with follow-up questioning. Journal of Environmental Economics and Management 30, $112-131$.

Hollard, G., Luchini, S., 1999. Théorie du choix social et représentations : analyse d'une enquête sur le tourisme vert en camargue. Working paper 99B06, Greqam, Université de la Méditerranée, Marseille, France.

Kahneman, D., Tversky, A., 2000. Choices, Values and Frames. New-York: Cambridge University Press.

Levin, I., Johnson, S., Gaeth, G.J., 1998. All frames are created equal : a typology and critical analysis of framing effects. Organizational Behavior and Human Decision Making Processes 71, 149-188.

List, J.A., 2003. Does market experience eliminate market anomalies? Quarterly Journal of Economics 118, 41-71.

List, J.A., 2004. Neoclassical theory versus prospect theory: Evidence from the marketplace. Econometrica 72, 615-625. 
MacFadden, D., Leonard, G., 1993. Issues in the contingent valuation of environmental goods: Methodologies for data collection and analysis. In: Hausman, J. (Ed), Contingent Valuation: a critical Assessment. New York: North-Holland, pp. 165-215.

Moscovici, S., 1961. La psychanalyse, son image et son public. Paris: Presses Universitaires de France.

Moscovici, S., 1998. Psychologie Sociale. Paris: Presses Universitaires de France.

Penz, E., Meier-Pesti, K., Kirchler, E., 2004. It's practical but no more controllable: Social representation of the electronic purse in Austria. Journal of Economic Psychology 25, 771-787.

Plott, C.R., Zeiler, K., 2005. The willingness to pay/willingness to accept gap, the endowment effect, subject misconceptions and experimental procedures for eliciting valuations. American Economic Review 95, 530-545.

Sayman, S., Öncüler, A., 2005. Effects of study design characteristics on the wta-wtp disparity: a meta analytical framework. Journal of Economic Psychology 26, 289312.

Shogren, J., Shin, S., Kliebenstein, J., Hayes, D., 1994. Resolving differences in willingness to pay and willingness to accept. American Economic Review 84, 255-270.

Slovic, P., 1991. The construction of preference. American Psychologist 50, 364-371.

Tversky, A., Kahneman, D., 1974. Judgment under uncertainty: Heuristics and biases. Science 185, 124-131.

Vergès, P., 1994. Approche du noyau central: propriétés quantitatives et structurales. In: Guimelli, C. (Ed), Structures et transformations des représentations sociales, Textes de base en Sciences Sociales. Lausanne: Delachaux et Niestlé, pp. 233-253.

Viaud, J., Roland-Levy, C., 2000. A positional and representational analysis of consumption: Households when facing debt and credit. Journal of Economic Psychology 21, 411-432.

Wagner, W., Duveen, G., Farr, R., Jovchelovitch, S., Lorenzi-Ciodo, F., Markova, I., Rose, D., 1999. Theory and method of social representations. Asian Journal of Social Psychology 2, 95-125.

Whitehead, J. C., 2002. Incentive incompatibility and starting-point bias in iterative valuation questions. Land Economics 78, 285-297.

Whitehead, J.C., 2004. Incentive incompatibility and starting-point bias in iterative valuation questions: reply. Land Economics 80, 316-319. 